Article

\title{
Chlorophyll-a Concentration Retrieval in the Optically Complex Waters of the St. Lawrence Estuary and Gulf Using Principal Component Analysis
}

\author{
Julien Laliberté $^{1, *}$, Pierre Larouche ${ }^{1}$, Emmanuel Devred ${ }^{2}$ and Susanne Craig ${ }^{3}$ \\ 1 Maurice-Lamontagne Institute, 850, route de la Mer, Mont-Joli, QC G5H 3Z4, Canada; \\ Pierre.Larouche@dfo-mpo.gc.ca \\ 2 Bedford Institute of Oceanography, 1 Challenger Dr, Dartmouth, NS B2Y 4A2, Canada; \\ Emmanuel.Devred@dfo-mpo.gc.ca \\ 3 Departments of Oceanography and Process Engineering and Applied Science, Dalhousie University, \\ 1355 Oxford Street, Halifax, NS B3H 4R2, Canada; susanne.craig@dal.ca \\ * Correspondence: Julien.Laliberte@gmail.com
}

Received:17 November 2017; Accepted: 3 February 2018; Published: 8 February 2018

\begin{abstract}
Empirical methods based on band ratios to infer chlorophyll-a concentration by satellite do not perform well over the optically complex waters of the St. Lawrence Estuary and Gulf. Using a dataset of 93 match-ups, we explore an alternative method relying on empirical orthogonal functions (EOF) to develop an algorithm that relates the satellite-derived remote sensing reflectances to in situ chlorophyll-a concentration for the Sea-viewing Wide Field-of-view Sensor (SeaWiFS). Results show that an accuracy of $41 \%$ at retrieving chlorophyll-a concentration can be reached using the EOF method compared to $140 \%$ for the widely-used Ocean Chlorophyll 4 (OC4v4) empirical algorithm, 53\% for the Garver-Siegel-Maritorena (GSM01) and 54\% for the Generalized Inherent Optical Property (GIOP) semi-analytical algorithms. This result is possible because the EOF approach is able to extract region-specific radiometric features from the satellite remote sensing reflectances that are related to absorption properties of optical components (water, coloured dissolved organic matter and chlorophyll-a) using the visible SeaWiFS channels. The method could easily be used with other ocean-colour satellite sensors (e.g., MODIS, MERIS, VIIRS, OLCI) to extend the time series for the St. Lawrence Estuary and Gulf waters.
\end{abstract}

Keywords: chlorophyll-a concentration; satellite remote sensing reflectance; St. Lawrence Estuary and Gulf; empirical orthogonal function analysis; coastal ocean; ocean colour

\section{Introduction}

The St. Lawrence Estuary and Gulf (SLEG), in Eastern Canada, is a large $\left(250,000 \mathrm{~km}^{2}\right)$ and complex coastal ecosystem where the biological, physical and chemical features are highly dynamic as a result of strong tides, winds, a high volume of freshwater runoff, complex bathymetry and winter sea ice [1,2]. Phytoplankton form the basis of this ecosystem. Their abundance is estimated by measuring the concentration of chlorophyll-a (photosynthetic pigment contained by all phytoplankton), a proxy for phytoplankton biomass [3]. Phytoplankton are primary producers [4,5] that transfer energy to higher trophic levels and export carbon to the deep ocean [6]. Knowledge of phytoplankton standing stock and distribution helps characterize the status of marine ecosystems, thereby facilitating their protection through sustainable management practices [7]. Phytoplankton are also sensitive indicators of changing chemical and physical conditions due to their short life cycles [8,9]. 
To our knowledge, the only peer-reviewed paper presenting a SLEG chlorophyll-a (Chl) climatology is based on a limited Coastal Zone Colour Scanner dataset (80 images) covering the years 1979-1981 [10]. Even though that work described the major features of Chl distribution in the SLEG (upwelling regions, mesoscale circulation), the results were based on a small number of images for each month (see their Table 1) and did not cover the entire seasonal cycle, with no data after September. Thus, there is a need to revise these results with a larger dataset covering a longer time frame. Constructing such a climatology from in situ data is difficult due to the relatively sparse spatial and temporal coverage of measurements over such a large extent. As shown by [10], satellite-derived Chl concentration could provide important information on the ecological status of the SLEG. However, this region is an optically complex marine environment [11] due to the presence of coloured dissolved organic matter (CDOM) derived from decaying organic matter and composed of humic and fulvic acids. Common CDOM sources include land runoff and the degradation products of phytoplankton. CDOM distribution is driven by the interplay of hydrodynamic mechanisms at different spatial and temporal scales and by exposure to ultraviolet (UV) light that causes photodegradation $[12,13]$. CDOM absorbs very strongly in the UV-blue region of the spectrum, competing with phytoplankton for the absorption of blue photons. As a result, when CDOM is present and does not covary with $\mathrm{Chl}$, blue-green band ratio algorithms are confounded, causing overestimation of Chl by as much as 400\% [14-18]. Previous studies that attempted to measure Chl using satellite ocean colour in these optically complex waters [18-20] indicated the need for more accurate retrieval algorithms in order to exploit this information for operational applications such as ecosystem and fisheries management. Precise estimation of $\mathrm{Chl}$ can also be used to provide environmental indicators of ecosystem health, to develop a response plan for ship-source oil pollution spill or detect changes related to climate variability [21]. Considering the poor performance of the Ocean Chlorophyll 4 (OC4v4) algorithm [18], the first step to derive robust seasonal climatologies, phytoplankton phenology, inter-annual trends and phytoplankton functional types is to establish a better inverse model to estimate $\mathrm{Chl}$ from remote sensing observations.

The goal of the current study is to develop a more accurate satellite-based regional Chl retrieval algorithm for the SLEG using a statistical approach. Tailored to specific optical conditions, regional models are a necessity to improve the interpretation of upwelling light from distinctively complex water bodies and are thus regularly published (e.g., [22-24]). We selected a method based on principal component analysis (also known as empirical orthogonal functions (EOF)) for its ability to capture the essential information contained in satellite-derived remote sensing reflectance (Rrs) spectra and relate it to Chl concentration [25]. The satellite-derived dominant information is related to coherent variations in measured $\mathrm{Chl}$ concentration via a multilinear regression model. This study thus reinforces the use of an easily-implementable PCA-type approach for inversion of geophysical variables [26-28]. Such an approach has the potential to significantly improve the reliability of Chl retrievals in the SLEG as shown recently for the optically complex waters of the Bedford Basin, Canada [29].

\section{Data and Method}

The EOF-based model was developed using a dataset covering the entire Sea-viewing Wide Field-of-view Sensor (SeaWiFS) era, and its performance is compared against standard and regionally-adapted $\mathrm{Chl}$ retrieval algorithms using an extensive in situ database. The use of SeaWiFS over other sensors such as the more recent Moderate Resolution Imaging Spectroradiometer (MODIS) was dictated by the large in situ measurement database that was assembled during the SeaWiFS era (1997-2010). SeaWiFS was also the first ocean colour sensor with high quality measurements (higher signal-to-noise ratio), precise calibration and improved spectral and spatial resolution that led to improved geophysical products compared to its predecessor, the Coastal Zone Color Scanner (CZCS), which operated between November 1978 and June 1986. 


\subsection{In Situ Data}

Surface measurements (2927 samples) of in situ Chl data collected by the Department of Fisheries and Oceans Canada were obtained from the St. Lawrence Global Observatory (SGBD) repository [30] for the years encompassing the SeaWiFS mission (1997-2010) and sampled in a region bounded from $45.5-50.5^{\circ} \mathrm{N}$ and $59.0-71.0^{\circ} \mathrm{W}$. The water samples were processed using fluorometric methods [31,32]. Samples were either processed onboard or frozen to be processed later in the laboratory. Usually, high-pressure liquid chromatography (HPLC) measurements are preferred over fluorometric methods to perform satellite validation exercises. Unfortunately, HPLC samples in the SLEG are too few to obtain a large enough match-up dataset. HPLC and fluorometric measurements are however very well correlated, with a log-linear regression $R^{2}$ of 0.88 , a slope of 0.995 and an intercept of 0.12 , $N=161$. Figure 1 shows that the dataset covers the entire ice-free season (April-November). The Chl concentration range is $\left[0.03,76.2 \mathrm{mg} \mathrm{chl} \mathrm{m}^{-3}\right]$ with a mean (median) value of $2.81(1.05) \mathrm{mg} \mathrm{chl} \mathrm{m}^{-3}$.
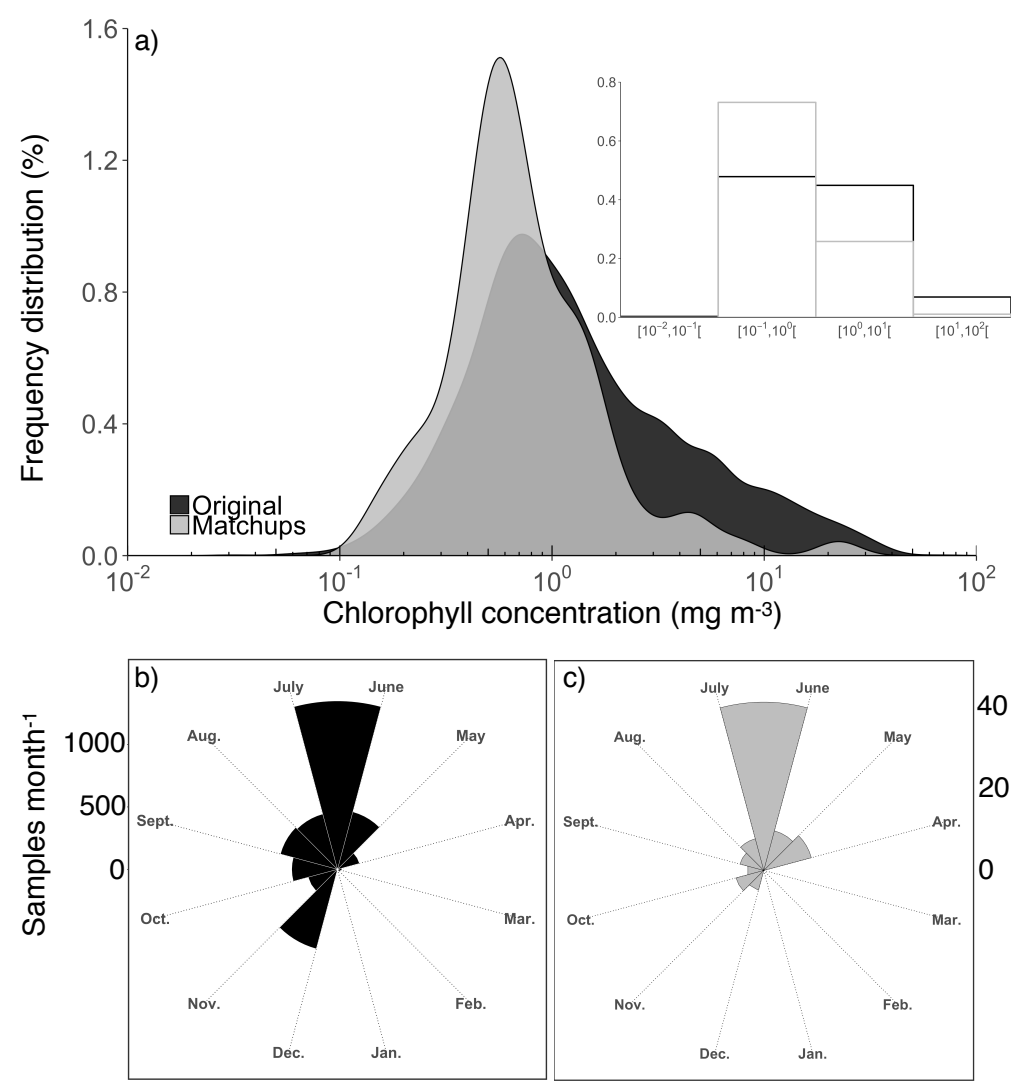

Figure 1. Frequency distribution of the 2927 original Chl measurements, 93 of which were considered valid match-ups. (a) Chl concentration frequency distributions (inset presents the same data binned by order of magnitude). Temporal distributions of $\mathrm{Chl}$ concentration for (b) the original and (c) match-up datasets.

\subsection{Match-Up Dataset}

The complex and dynamic SLEG ecosystem requires the use of the highest available spatial and temporal resolution images to capture small-scale and short-term events and minimize errors when applying non-linear models. We used SeaWiFS Level-1A MLAC (Merged Local Area Coverage, 1.1-km spatial resolution at nadir) data downloaded from NASA's Ocean Biology Processing Group (OBPG) website [33], which were processed using the SeaWiFS Data Analysis System (SeaDAS, Version 7.3.2) software to derive Rrs. A window of \pm 3 -h $\mathrm{h}$ between in situ data collection and satellite overpass was used to perform the match-up effort as recommended [34]. This time window represents a good 
compromise between maximizing the number of match-ups and minimizing the spatio-temporal variability of the SLEG when comparing satellite and in situ measurements. A $3 \times 3$ pixel matrix centered on each in situ sample in the database was extracted from each concomitant satellite pass. This area $\left(9 \mathrm{~km}^{2}\right)$ was considered large enough to average out small-scale variability in the SLEG [35]. It also reduces potential satellite navigation errors. Any spectrum with negative values was removed, as these likely presented pixels where the atmospheric correction process failed. Match-ups were kept when 6 out of 9 pixels were valid. For each match-up, we used the median of the positive Rrs spectra with non-flagged pixel values. All SeaDAS default flags were used during the processing, including atmospheric correction failure, stray light, sun glint and possible sea ice or cloud contamination. The final dataset was composed of 93 valid match-ups from 67 overpasses out of the initial 2927 samples. This comparatively small set of valid data points emphasizes the impact of cloud cover on satellite ocean colour potential and the challenges of atmospheric correction in the validation of geophysical products in coastal zones.

Figures 1 and 2 show that despite the small number of data, the match-up dataset retains similar properties to the original larger SGDB dataset in terms of concentration distribution, temporal distribution and spatial coverage of the Chl. The match-up dataset is spatially homogeneous, but biased towards the June period (typically bloom or post-bloom conditions). Compared to the initial dataset, fewer match-ups were found for November as a result of cloud cover and low sun elevation, which limits the number of good images. The range of $\mathrm{Chl}$ concentration for the match-up dataset is $\left[0.14,22.4 \mathrm{mg} \mathrm{chl} \mathrm{m}^{-3}\right.$ ] with a mean (median) value of $1.20(0.62) \mathrm{mg} \mathrm{chl} \mathrm{m}^{-3}$. The maximum value of $22.4 \mathrm{mg} \mathrm{chl} \mathrm{m}^{-3}$ was collected on 31 May 1999 at a station periodically sampled in the St. Lawrence estuary $\left(48.66^{\circ} \mathrm{N}, 68.58^{\circ} \mathrm{W}\right)$, which is known to reach high values during the spring bloom [36]. The match-up dataset therefore adequately represents the SLEG in terms of geographic coverage and phytoplankton dynamics.

\subsection{Atmospheric Correction}

A critical step of ocean colour data processing is to generate the most accurate $R r s\left(\mathrm{sr}^{-1}\right)$ defined as:

$$
\operatorname{Rrs}(\lambda)=\frac{L_{w}\left(\lambda, 0^{+}\right)}{E_{d}\left(\lambda, 0^{+}\right)}
$$

where $L_{w}$ is the water-leaving radiance $\left(\mu \mathrm{W} \mathrm{cm} \mathrm{cm}^{-1} \mathrm{sr}^{-1}\right), E_{d}$ is the downwelling irradiance $\left(\mu \mathrm{W} \mathrm{cm}{ }^{-2} \mathrm{~m}^{-1}\right)$ at the sea surface $\left(0^{+}\right)$and $\lambda(\mathrm{nm})$ is the wavelength of interest.

Ocean colour sensors measure the radiant energy reflected by the Earth-atmosphere system, so the contribution from the atmosphere to the total signal reaching the sensor must be removed. Because this correction depends not only on illumination conditions and atmospheric composition, but also on the water-type, we characterized the optical signature of the SLEG waters using the approach from [37]. This method uses the relation between a proxy for the relative abundance of CDOM to Chl $(\operatorname{Rrs}(412) / \operatorname{Rrs}(443))$ and a proxy for Chl concentration $(\operatorname{Rrs}(555) / \operatorname{Rrs}(490))$, as these two quantities are very well correlated in Case-1 waters (black line in Figure 2a). Applying that method on the SeaWiFS climatological Rrs data available from the OBPG website [38], it is clear that almost all the SLEG data fall outside the area considered by [37] as representative of Case-1 waters (Figure 2a, purple interval) and for which the optical properties are solely determined by Chl. Figure $2 \mathrm{~b}$ maps the normalized distance between a point and the perfect Case-1. In Figure 2 the colours represent the distance between the retrieved climatological Rrs value and the black line (i.e., $\operatorname{Rrs}(412) / \operatorname{Rrs}(443)$, theoretical perfect case-1), normalized by the width of the purple interval for this Chl concentration. This colour coding does not present absolute quantitative information, but rather a guide to illustrate the spatial contrast in the division of the relative abundance of CDOM to Chl, an indicator of the water type. It is clear from this figure that Rrs is influenced by CDOM to a far greater degree than by phytoplankton, such that the SLEG cannot be considered Case-1 water. This result is consistent with the optical classification of coastal waters performed by [11] where the SLEG Rrs spectral shapes were 
classified as waters dominated by CDOM absorption. According to [39], the standard NIR-iteration atmospheric correction (AC) procedure [40-42] is more suited to CDOM-dominated waters than the Management Unit of the North Sea Mathematical Models (MUMM) AC [43], which was developed for turbid waters dominated by mineral particles. Considering the low concentration of suspended particulate matter (SPM) measured over most of the SLEG [44], the standard NIR-iteration AC was used to process the SeaWiFS images.
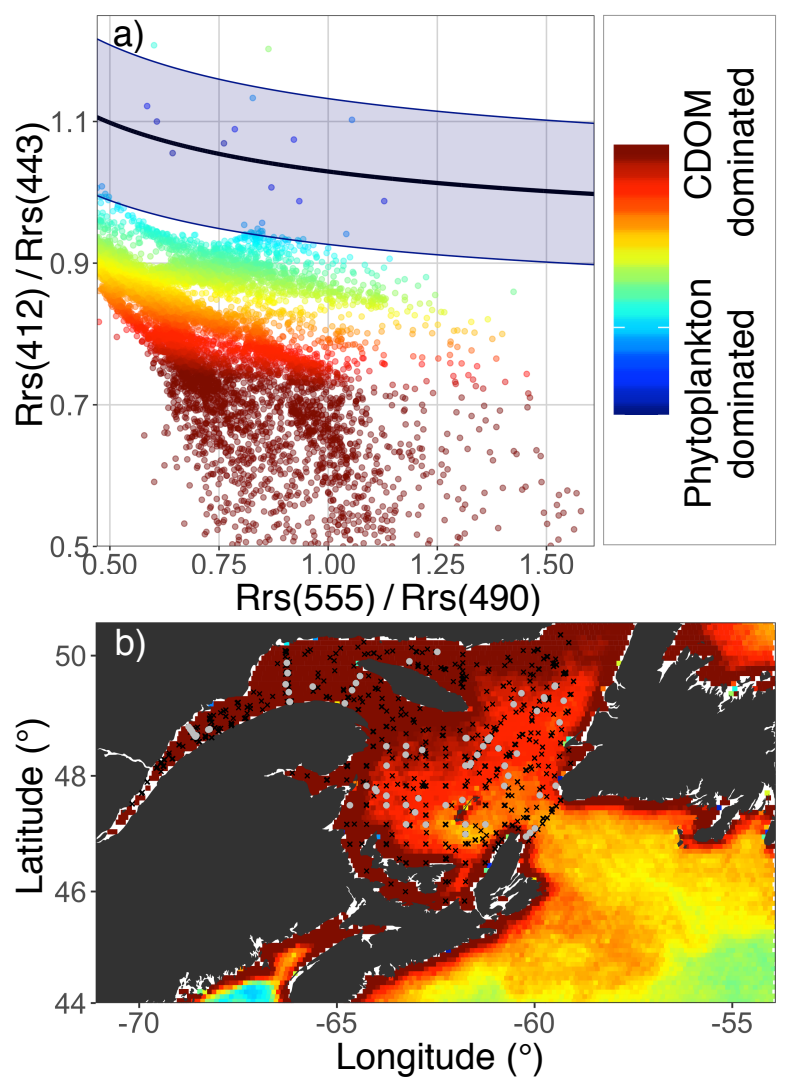

Figure 2. Representation of the different water-types. (a) Classification of the SLEG climatological Rrs using the methodology of [37]. The black line represents the perfect Case-1 relation between $\operatorname{Rrs}(412) / \operatorname{Rrs}(443)$ and $\operatorname{Rrs}(555) / \operatorname{Rrs}(490)$. (b) Map of the normalized difference between the climatological SeaWiFS Rrs spectra and the perfect Case-1 line (see the text), with black crosses representing the location of the original $\mathrm{Chl}$ samples and grey dots representing the retained $\mathrm{Chl}$ samples. The same colour scale applies to both panels.

\subsection{Performance Evaluation}

To assess agreement between measured and predicted Chl, the mean bias (a measure of the systematic error; Equation (2)), the root mean squared error (RMSE, a measure of accuracy; Equation (3)) and the absolute mean percentage difference (APD, a measure of accuracy as a percentage; Equation (4)), similar to the relative error (RE, a measure of accuracy of each estimate as a percentage; Equation (5)), were calculated using the following equations:

$$
\begin{aligned}
\text { Bias } & =\frac{\sum\left(\log _{10} C h l_{\text {estimated }}-\log _{10} C h l_{\text {measured }}\right)}{N} \\
R M S E & =\sqrt{\frac{\sum\left(\log _{10} C h l_{\text {estimated }}-\log _{10} C h l_{\text {measured }}\right)^{2}}{N-2}}
\end{aligned}
$$




$$
\begin{aligned}
A P D & =\frac{100}{N} \sum \frac{\mid C h l_{\text {estimated }}-C_{\text {measured }}}{C h l_{\text {meased }} \mid} \\
R E & =100 \frac{\mid \text { Chl } l_{\text {estimated }}-C h l_{\text {measured }} \mid}{C h l_{\text {measured }}}
\end{aligned}
$$

We also used the slope, intercept and $R^{2}$ values of the calculated log-linear relationships to evaluate the performance of the various algorithms. We applied a reduced major axis (RMA) regression model of Type II (R package lmodel2, [45]) to derive the slopes and intercepts of the regressions.

\section{Results}

\subsection{Performance of Generic Algorithms}

Prior to developing a new algorithm, we tested three Chl algorithms (OC4v4, GSM01, GIOP), which are readily available in SeaDAS. Figure 3a shows that the SLEG dataset is very different from the global dataset used to develop the OC4v4 algorithm, which attests to the strong impact of CDOM absorption on the remote sensing signal (Figure 2). Several studies showed that global empirical relationships do not perform well when external sources of organic and inorganic compound are present $[20,46,47]$. As expected, the OC4v4 algorithm overestimates Chl in the SLEG with an APD of $140 \%$ (Table 1). This value can be compared to validation exercises carried out in other coastal environments such as the Baltic Sea ( $\approx 159$ to $201 \%$ overestimation) [16,48], the southeastern Beaufort Sea $(188 \%)$ [49], the La Plata estuary (106-250\%) [50] and the Black Sea ( $\approx 400 \%)$ [51]. Many site-specific empirical relationships between ratios of Rrs at different wavebands and in situ measurements of Chl have been derived in previous studies $[16,48,49,52,53]$. Local tuning methods have the great advantage of being very simple to implement with the model parameters being optimized for a given dataset. This type of approach removes or decreases systematic bias in the Rrs due to other components than phytoplankton because the fit provides the average trend of the data. An attempt was thus made to use the band-ratio approach using the SLEG match-up dataset. Figure 3a shows that the distribution of the 93 match-ups contains both low and high Chl values for a given band ratio. Tests showed that fitting the data with higher order polynomial functions (quadratic, cubic, fourth and fifth order) did not yield significantly better performance than the simple linear regression $(p>0.05)$. Similar conclusions were drawn by [54] for the Beaufort and Chukchi seas and by [48] for Baltic waters. The band-ratio algorithm that resulted in the best performance (RMSE, APD and $\mathrm{R}^{2}$, Figure $3 \mathrm{~b}$ and Table 1 ) for the SLEG is therefore the linear regression:

$$
\log _{10} \text { Chl } l_{\text {stimated }}=a_{0}+a_{1} X
$$

where $a_{0}=0.047, a_{1}=-2.1$ and $X$ is the $\log _{10}$ of the maximum of $\operatorname{Rrs}(443) / \operatorname{Rrs}(555), \operatorname{Rrs}(490) / \operatorname{Rrs}(555)$ or Rrs(510)/Rrs(555). The Ocean Chlorophyll 4 Linear (OC4L) algorithm provides better estimates of Chl than the OC4v4 (Table 1) with an RMSE of $0.29 \log _{10} \mathrm{mg} \mathrm{chl} \mathrm{m}^{-3}$, an APD of $56 \%$ and an $\mathrm{R}^{2}$ of 0.35 . Yet, the results suggest that even a local optimization process for the SLEG does not lead to satisfactory results in assessing the status of ocean biota since this approach does not provide the ability to remove the contribution from other components than $\mathrm{Chl}$ concentration to the total reflectance signal. 


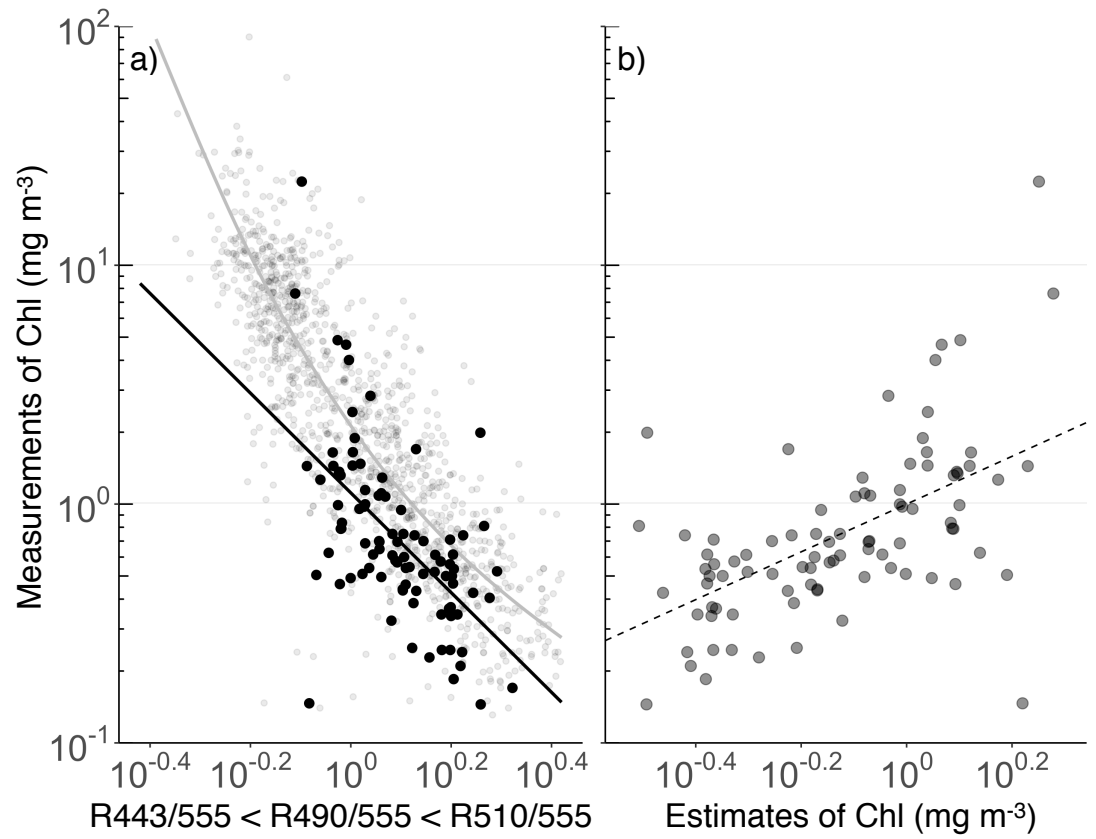

Figure 3. Band ratio algorithms. (a) Comparison of the St. Lawrence Estuary and Gulf (SLEG) match-ups (black dots) and SeaBASS [55] datasets (light grey dots). The grey line corresponds to the OC4v4 polynomial fit, and the black line is the linear regression of in situ Chl and corresponding SLEG remote sensing reflectances ratios, with $\operatorname{R443/555}=\operatorname{Rrs}(443) / \operatorname{Rrs}(555), \operatorname{R490} / 555=\operatorname{Rrs}(490) / \operatorname{Rrs}(555)$ and $\mathrm{R} 510 / 555=\operatorname{Rrs}(510) / \operatorname{Rrs}(555)$. (b) Scatterplot of in situ versus satellite-derived Chl using the OC4L algorithm.

Table 1. Performance of the various algorithms tested. OC4v4, OC4L, GSM01, GIOP and EOF are the Ocean Chlorophyll 4, Ocean Chlorophyll 4 Linear, Garver-Siegel-Maritorena, Generalized Inherent Optical Property and empirical orthogonal function algorithms.

\begin{tabular}{|c|c|c|c|c|c|c|c|c|}
\hline Method & $R^{2}$ & Bias (log $\left.\mathrm{mg} \mathrm{m}^{-3}\right)$ & RMSE $\left(\log \mathrm{mg} \mathrm{m}^{-3}\right)$ & APD (\%) & $\mathbf{N}$ & $\% \mathrm{~N}<50 \%$ Error & Slope & Intercept \\
\hline OC4v4 & 0.36 & 0.24 & 0.38 & 140 & 93 & 34 & 0.72 & 0.2 \\
\hline OC4L & 0.35 & $\approx 0$ & 0.29 & 56 & 93 & 66 & 0.59 & -0.059 \\
\hline GSM01 & 0.27 & -0.073 & 0.33 & 53 & 58 & 59 & 1.1 & -0.065 \\
\hline GIOP & 0.22 & -0.083 & 0.38 & 54 & 64 & 52 & 1.2 & -0.041 \\
\hline EOF & 0.65 & $\approx 0$ & 0.22 & 41 & 93 & 71 & 0.8 & -0.028 \\
\hline
\end{tabular}

Two semi-analytical algorithms available in SeaDAS were also tested. The Garver-SiegelMaritorena version 1 (GSM01) [56] algorithm was mostly developed using an oceanic dataset, and the Generalized Inherent Optical Property (GIOP) [57] algorithm has been recently developed to provide better performances in coastal waters. Unlike OC4-type algorithms, the GSM01 and GIOP algorithms use Rrs absolute values rather than band ratios. A semi-analytical reflectance model is coupled to an optimization algorithm (e.g., Levenberg-Marquardt method) to find the best set of Chl concentration, yellow substance absorption and particulate backscattering that will minimize the quadratic difference between measured and modeled Rrs. In theory, this type of algorithm decouples the contribution from CDOM and phytoplankton, making it suitable for coastal waters. Nevertheless, it requires a priori knowledge of the spectral shape of absorption and backscattering of the marine components, which can lead to increased errors in the retrieved information when the spectral dependence contains bias. Table 1 shows that both semi-analytical approaches (GSM01 and GIOP) perform relatively well in the SLEG with an APD of 53\% and 54\%, respectively. In other coastal environments, results obtained from the GSM01 algorithm $[49,50,52]$ indicated significant overestimation of Chl $(96-121 \%$ in the La Plata estuary, $49 \%$ in the Chesapeake Bay, 101\% the Beaufort Sea). Both GSM01 and GIOP did not performed well in the South China Sea even when using in situ Rrs [58]. Together, the results obtained with the 
OC4v4, OC4L and the two semi-analytical algorithms indicate that there is still room for improvement in the precision of Chla estimation in the SLEG and justifies the need to develop a SLEG-specific algorithm that relies on a different approach.

\subsection{Development of a Chlorophyll Algorithm Using EOF}

The approach of [29] (hereafter referred to as EOF) demonstrated two important results when applying non-parametric statistical methods to inversion of the ocean colour signal. First, it is possible to build a stable model to derive Chl concentration from a small training set of remote sensing reflectances $(<30)$, and second, multispectral resolution (SeaWiFS-like channels) shows similar capability as hyperspectral resolution when inferring Chl concentration from Rrs.

The 93 Rrs match-ups for the six SeaWiFS wavelengths were aggregated into a single matrix $(93 \times 6)$, which was log-transformed to avoid a skewed distribution. No spectral normalization was performed as this did not improve the results. A principal components analysis was performed on this matrix with the principal function from the psych package in R [59]. The log-linearized and correlated visible channels were transformed into linearly-independent principal components (also called modes of oscillation) that represent the global covariance structure of the Rrs. The primary mode of oscillation accounts for maximum variability of Rrs and each successive (subordinate) mode accounts for as much of the remaining variability as possible.

A full linear model was first constructed using all of the available six modes. The model was then constructed by performing the Akaike information criterion (AIC)-based stepwise regression (MASS package in R, [60]), which attempts to find the best variable selection by adding and removing modes, keeping the model as simple as possible. A minimum AIC value is a balance between model data fit and a penalty based on the number of dependent variables [61]. Chl estimates were thereby derived by performing a multilinear regression with the smallest AIC value using the scores from the selected modes:

$$
\log _{10} \text { Chl }_{\text {estimated }}=B_{0}+\sum_{i=1}^{N} B_{i} S_{i}
$$

where $B_{i}$ are the coefficients, $N$ is the number of retained modes ( $N \leq 6$, corresponding to the number of visible channels of SeaWiFS) and $S_{i}$ are the score vectors. For our complete dataset (Section 2.2), the final model is the same as the full one, meaning all modes parsimoniously explain variance in $\mathrm{Chl}$ within the training dataset [62]. Besides, all predictors of the regression are significant $(p<0.05)$. To validate the approach of [29] where the subordinate modes are sometimes removed, we carried out a cross-validation exercise where the full scores were divided into a training sample to define a multilinear regression and a test sample to evaluate the method. Minimum and maximum training data were 20 and $80 \%$, respectively. This exercise was performed 1000 times for each sample size, with $1 \%$ increments, choosing the most important modes generated from the stepwise AIC criterion-based procedure (generally between two and six). For every iteration, the fewest number of modes was balanced against the prediction power, using a combination of forward selection and backward elimination of the potential predictors [60]. The $B_{i}$ coefficients of the selected models were used with all Rrs-derived score vectors to predict Chl estimates. Figure 4a shows the stepwise regression method (selection of the lowest AIC model) and its performance improvements as a function of the training data size (\%). Stable performance was reached once $50 \%$ of the training dataset was used (i.e., $\sim 47$ match-ups). This cross-validation exercise allows insight into the stability of the model when it comes to the number of match-ups needed to represent temporal and spatial Chl sampling constraints shown in Figures 1 and 2.

The performance of the EOF algorithm is shown in Figure $4 \mathrm{~b}$ and Table 1. There is a good improvement over the OC4L and the two semi-analytical algorithms with an RMSE of $0.22 \log _{10}$ $\mathrm{mg} \mathrm{chl} \mathrm{m}{ }^{-3}$, an APD of $41 \%$ and a $\mathrm{R}^{2}$ of 0.65 . The slope and intercept values are also better than the OC4L. 

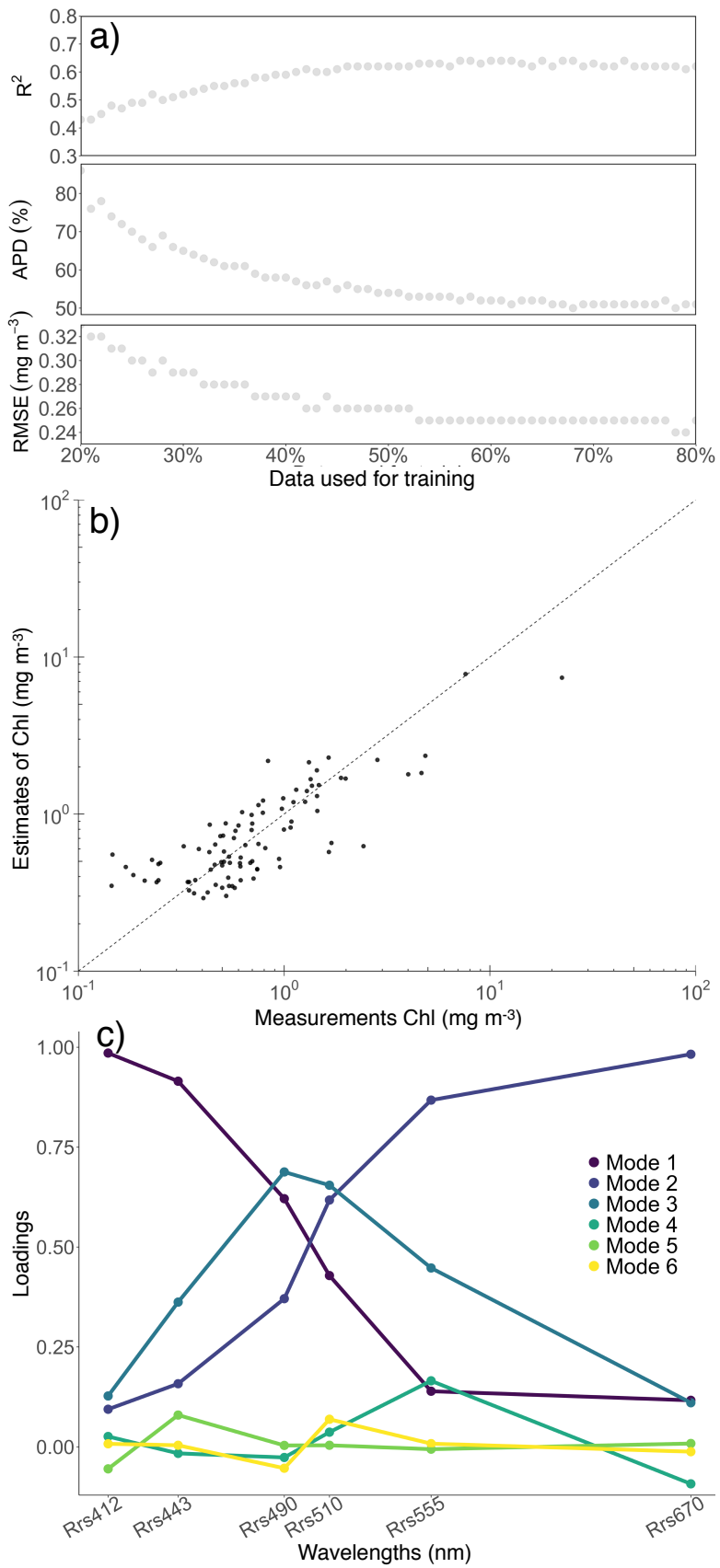

Figure 4. Features of the EOF method: (a) stability of the EOF; (b) scatter plot of in situ Chl versus satellite-derived Chl using the EOF, with the dashed line as the 1:1 ratio; (c) all modes of oscillation (solid coloured lines are linear interpolation over wavelengths of the discrete spectral data and are used as a guide to aid visualizing the spectral signature).

\section{Discussion}

In the optically complex SLEG region, the EOF model has considerable advantages over band ratio algorithms. Valuable information is retained by using the six SeaWiFS channels. In the dataset, the further apart the channels, the less correlated they are (correlation matrix not shown), meaning a higher variance should emerge from incorporation of the marginal channels. The blue channel $(412 \mathrm{~nm})$ probably records variations that are not directly related to Chl concentration variations, but rather to CDOM absorption, which should partly blend with the usual phytoplankton blue dominant absorption peak at $443 \mathrm{~nm}$. At the other end of the spectrum, although the added red channel $(670 \mathrm{~nm})$ 
is dominated by water absorption, a smaller, but interesting contribution can also appear from the chlorophyll-a absorption band centered at $675 \mathrm{~nm}$.

Figure 4c shows the six modes of oscillation derived from the Rrs matrix. Rrs being a function of both absorption and backscattering, its variations are thus regulated by spectral variations of inherent optical properties [63]. Backscattering should not show strong variations in the SLEG due to very low SPM concentrations [44], leaving absorption as the primary source of spectral variability. The work in [47] showed the contributions from different optical components to the absorption spectrum based on 371 in situ surface absorption measurements from all the major ocean basins. According to these results, our principal modes of oscillation can be attributed to the fraction of contribution to the total absorption by CDOM (Mode 1, 66\% of variance explained), water (Mode 2, 29\% of variance explained) and phytoplankton (Mode 3, 4.1\% of variance explained), while Mode 4 (0.5\% of variance explained) mostly represents SeaWiFS variations in the red channel and, to a lesser extent, the green channel. The spectral behaviour of the red phytoplankton absorption peak is known to vary for different species $[64,65]$. The minor variations in the red could therefore be caused by different species and provide a very slight, but superior prediction ability when this variance is integrated with the model. Considering the weak visible absorption of detrital particles in the SLEG $\left(a_{n a p}(440)=0.031\right.$, $N=148$, [13]), it is unclear if subordinate modes should be associated with a definitive variation of optical property (Modes 5 and 6 together account for $<0.3 \%$ of the variance).

The EOF model is a superior predictor for Chl concentration retrieval in the SLEG for the SeaWiFS data, as it separates the misleading spectral effects from the other major optically-active component (CDOM). Overall, EOF statistics show a better performance than all the other tested algorithms. The log-based bias and RMSE of the EOF method highlight its ability to operate well across the dynamic range of our $\mathrm{Chl}$ match-ups ( $\sim 2$ orders of magnitude). Considering the small magnitude of the values involved in the calculation of the APD and the precision of the in situ fluorometric measurements, these results are encouraging. As shown in Figure 5, the model performance was further evaluated by examining the relative error (1) as a function of the Chl concentration, to assess whether the algorithm was consistent for the entire range of variation of Chl concentration and (2) as a function of the geographical location of the match-ups.

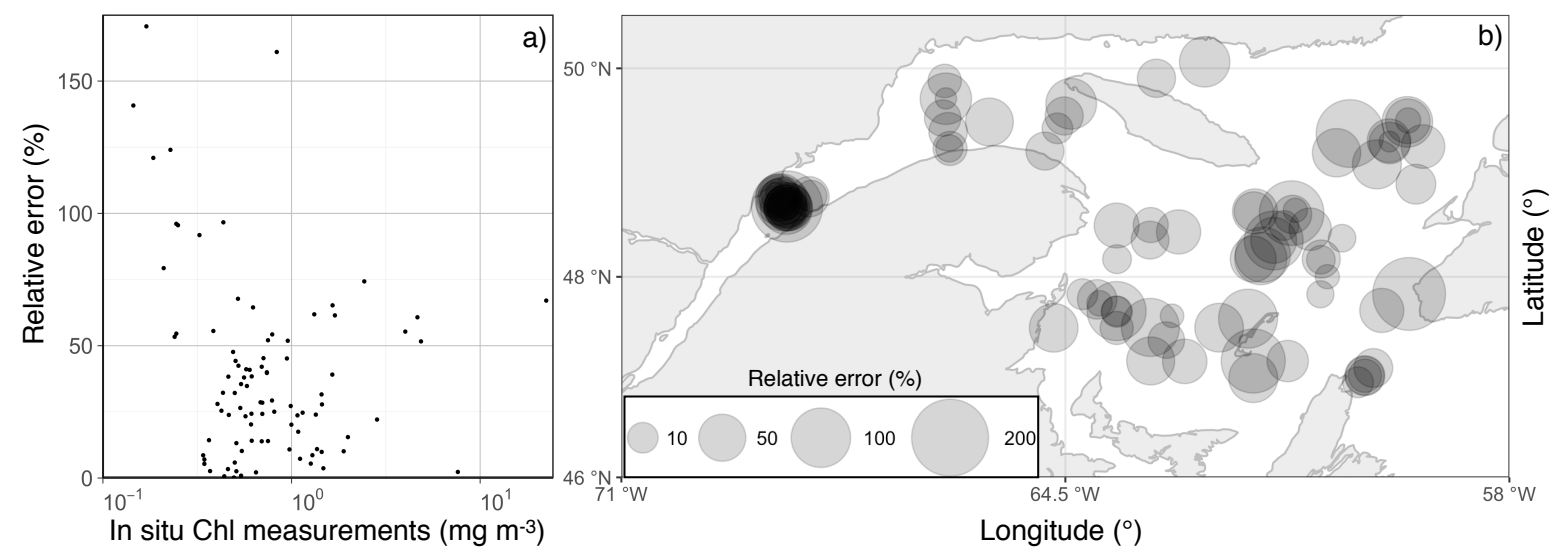

Figure 5. Relative error as a function of (a) Chl concentration and (b) spatial distribution.

Chl concentrations used to develop the EOF model span over a limited range with few values above $3 \mathrm{mg} \mathrm{m}^{-3}$ (Figure 5a). The EOF model may thus not adequately capture the magnitude of the Rrs spectra variations for more eutrophic waters. This is a limit inherent to any empirical method that will only perform well in the range of data that were used to develop it. Figure 5 a also shows that the largest relative errors ( $>100 \%$ ) are mostly limited to Chl concentrations lower than $0.5 \mathrm{mg} \mathrm{m}^{-3}$. Table 1 shows that most $(71 \%)$ of the EOF predictions remain under $50 \%$ relative error. Figure $5 \mathrm{~b}$ shows that no obvious large-scale spatial pattern appears in the geographic relative error distribution. In the St. 
Lawrence Estuary where there is a high density of match-ups, only two of the 21 retrievals yield a relative error above $80 \%$. The EOF approach does not appear to have major geographical bias over SLEG waters.

Previous attempts at estimating $\mathrm{Chl}$ in the SLEG from satellite remote sensing showed the difficulty in achieving reasonable accuracy. The work in [18] tested several models using fluorometric $\mathrm{Chl}$ values and a wide variety of band ratios and band differences. Their results showed that an algorithm based on two band-ratios (Rrs443/Rrs510 and Rrs443/Rrs555) yielded an estimation error of $70 \%$ using in situ radiometric measurements and $95 \%$ when using SeaWiFS-derived Rrs. Other studies in optically complex coastal waters showed that it is often necessary to avoid band-ratio-based algorithms to better reflect the specificity of the local/regional biophysical characteristics [66-70]. As part of the CoastColor validation program, the accuracy of a neural network approach was applied to MERIS to estimate Chl. When evaluated with a network of moored buoys (Larouche, unpublished) it was shown inadequate for the SLEG, yielding accuracies of about $300 \%$. The EOF method is thus the most appropriate $\mathrm{Chl}$ algorithm developed for the SLEG to date and is a major improvement over operational or other past regional algorithms.

Figure 6 shows the application of the EOF method on an L2 image acquired in the fall of 2003. Values below 0.1 and above $10 \mathrm{mg} \mathrm{chl} \mathrm{m}^{-3}$ (representing $<0.07 \%$ of the Chl estimates) were removed to effectively depict $\mathrm{Chl}$ patterns. The image displays strong spatial variability of $\mathrm{Chl}$ concentration in the SLEG, including mesoscale features in the estuary part.

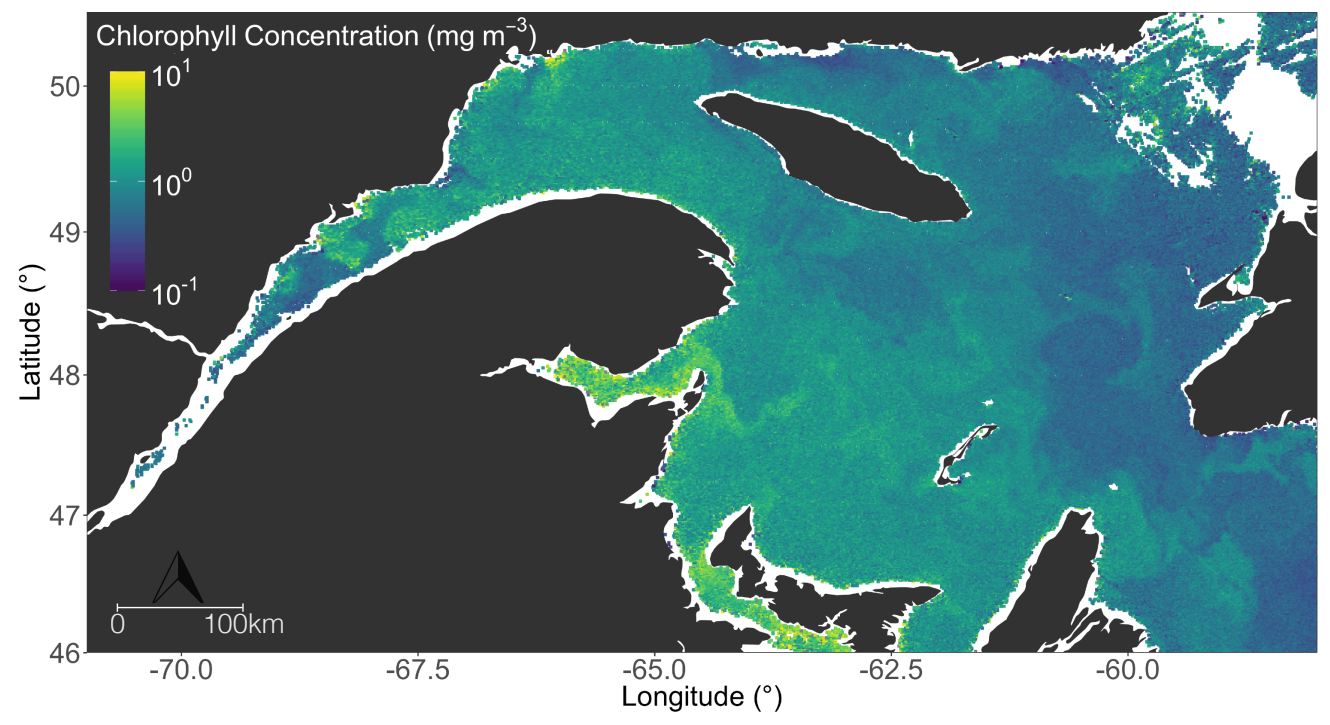

Figure 6. SLEG chlorophyll for 12 October 2003, as predicted by the EOF algorithm.

One of the reasons why our dataset was limited to 93 match-ups is atmospheric correction (AC) failures. Addressing the AC challenge in the SLEG should provide a major improvement in future algorithm development for these optically complex waters. Local measurements for developing such a regionally-specific AC scheme were recently derived by [71].

\section{Conclusions}

A method based on empirical orthogonal functions was used to improve the accuracy at which chlorophyll-a (Chl) concentrations can be retrieved for the optically complex St. Lawrence Estuary and Gulf. The main strength of the method lies in its ability to decouple the different contributors (i.e., water, yellow substances, phytoplankton) to the total reflectance signal. The $\mathrm{Chl}$ concentration retrieval accuracy was greatly improved from $140 \%$ using the OC $4 \mathrm{v} 4$ band-ratio approach to $41 \%$. In addition, the EOF method did not show any spatial bias, making it applicable to the entire region of 
interest. The third report from the International Ocean-Colour Coordinating Group [72] stresses the need for new algorithms and a fresh approach to derive information from optically complex waters. A major impediment for such an endeavour is the lack of in situ data publicly available for research. With the increasing popularity of the SeaBASS dataset, the EOF method could easily be applied to global data. Conjointly, water-type tuning could also help improve algorithm performance. Our work using the SeaWiFS ocean colour satellite was a proof of concept. The same approach could in fact be applied to other satellite sensors (MODIS, MERIS, VIIRS, OLCI) given that a sufficiently large match-up dataset is assembled. This would extend the time series from 2010 to present day. Implementing the method using data from several ocean colour satellites would also help overcome some of the temporal limitations by taking advantage of different equatorial crossing time, filing inter-orbit gaps and limiting sun glint effects.

Acknowledgments: The authors are grateful to Eric Rehm for his insightful comments and revision of the manuscript. We are thankful to NASA's Ocean Biology Processing Group and the Dept. of Fisheries and Oceans Canada, the St. Lawrence Global Observatory and especially to Laure Devine. The work was supported by the Fonds de recherche du Québec - Nature et technologies and Québec-Océan. All the information needed to reconstruct the EOF algorithm is available upon request from the authors.

Author Contributions: Julien Laliberté processed the data and wrote the paper. Pierre Larouche also wrote the paper. Emmanuel Devred helped with data processing and revised the manuscript. Susanne Craig developed the original method.

Conflicts of Interest: The authors declare no conflict of interest.

\section{References}

1. Savenkoff, C.; Bourassa, M.N.; Baril, D.; Benoît, H.P. Identification of Ecologically and Biologically Significant Areas for the Estuary and Gulf of St. Lawrence; Technical report; Canadian Science Advisory Secretariat: Ottawa, ON, Canada, 2007; pp. 1-49.

2. Lavoie, D.; Starr, M.; Zakardjian, B.; Larouche, P. Identification of Ecologically and Biologically Significant Areas (EBSA) in the Estuary and Gulf of St. Lawrence: Primary Production; Technical report; Canadian Science Advisory Secretariat: Ottawa, ON, Canada, 2007; pp. 1-29.

3. Cullen, J.J. The Deep Chlorophyll Maximum: Comparing Vertical Profiles of Chlorophyll a. Can. J. Fish. Aquat. Sci. 1982, 39, 791-803.

4. Smith, R.C.; Eppley, W.; Baker, K.S. Correlation of primary production as measured aboard in Southern California coastal waters and as estimated from satellite chlorophyll images. Mar. Biol. 1982, 66, 1-8.

5. Platt, T.; Herman, A.W. Remote sensing of phytoplankton in the sea: Surface-layer chlorophyll as an estimate of water-column chlorophyll and primary production. Int. J. Remote Sens. 1983, 4, 343-351.

6. Laws, E.A.; Falkowski, P.G.; Smith, W.O.; Ducklow, H.; McCarthy, J.J. Temperature effects on export production in the open ocean. Glob. Biogeochem. Cycles 2000, 14, 1231-1246.

7. Wilson, $\mathrm{C}$. The rocky road from research to operations for satellite ocean-colour data in fishery management. J. Mar. Sci. 2001, 68, 677-686.

8. Côté, B.; Platt, T. Day-to-day variations in the spring-summer photosynthetic parameters of coastal marine phytoplankton. Limnol. Oceanogr. 1983, 28, 320-344.

9. VonDassow, P.; Montresor, M. Unveiling the mysteries of phytoplankton life cycles: patterns and opportunities behind complexity. J. Plankton Res. 2011, 33, 3-12.

10. Fuentes-Yaco, C.; Vezina, A.; Larouche, P.; Vigneau, C.; Gosselin, M.; Levasseur, M. Phytoplankton pigment in the Gulf of St. Lawrence, Canada, as determined by the Coastal Zone Color Scanner-Part 1: Spatio-temporal variability. Cont. Shelf Res. 1997, 17, 1421-1439.

11. Mélin, F.; Vantrepotte, V. How optically diverse is the coastal ocean? Remote Sens. Environ. 2015, 160, 235-251.

12. Nieke, B.; Reuter, R.; Heuermann, R.; Wang, H.; Babin, M.; Therriault, J.C. Light absorption and fluorescence properties of chromophoric dissolved organic matter (CDOM) in the St. Lawrence Estuary (Case 2 waters). Cont. Shelf Res. 1997, 17, 235-252.

13. Çizmeli, S.A. Parameterization, Regionalization and Radiative Transfer Coherence of Optical Measurements Acquired in the St-Lawrence Ecosystem. Ph.D. Thesis, Université de Sherbrooke, Sherbrooke, QC, Canada, 2008. 
14. Carder, K.L.; Steward, R.G.; Harvey, G.R.; Ortner, P.B. Marine humic and fulvic acids: Their effects on remote sensing of ocean chlorophyll. Limnol. Oceanogr. 1989, 34, 68-81.

15. Dall'Olmo, G.; Gitelson, A.A.; Rundquist, D.C.; Leavitt, B.; Barrow, T.; Holz, J.C. Assessing the potential of SeaWiFS and MODIS for estimating chlorophyll concentration in turbid productive waters using red and near-infrared bands. Remote Sens. Environ. 2005, 96, 176-187.

16. Darecki, M.; Stramski, D. An evaluation of MODIS and SeaWiFS bio-optical algorithms in the Baltic Sea. Remote Sens. Environ. 2004, 89, 326-350.

17. Hu, C.; Muller-Karger, F.E.; Biggs, D.C.; Carder, K.L.; Nababan, B.; Nadeau, D.; Vanderbloemen, J. Comparison of ship and satellite bio-optical measurements on the continental margin of the NE Gulf of Mexico. Int. J. Remote Sens. 2003, 24, 2597-2612.

18. Yayla, K.M. Approche Empirique de la Télédétection de la Chlorophylle D'eaux à Complexité Optique Dans L'estuaire et le Golfe du Saint-Laurent. Ph.D. Thesis, Université de Sherbrooke, Sherbrooke, QC, Canada, 2009.

19. Jacques, A. La Télédétection Passive de la Chlorophylle Dans L'estuaire Maritime du Saint-Laurent Optimisation Spectrale Des Algorithmes et Application au SeaWiFs. Ph.D. Thesis, Université de Sherbrooke, Sherbrooke, QC, Canada, 2001.

20. Gregg, W.W.; Casey, N. Global and regional evaluation of the SeaWiFS chlorophyll data set. Remote Sens. Environ. 2004, 93, 463-479.

21. IOCCG. Why Ocean Colour? The Societal Benefits of Ocean-Colour Technology In Reports of the International Ocean Colour Coordinating Group; Platt, T., Hoepffner, N., Stuart, V., Brown, C., Eds.; IOCCG: Dartmouth, NS, Canada, 2008; Volume 7.

22. Loisel, H.; Vantrepotte, V.; Ouillon, S.; Ngoc, D.D.; Herrmann, M.; Tran, V.; Mériaux, X.; Dessailly, D.; Jamet, C.; Duhaut, T.; et al. Assessment and analysis of the chlorophyll-a concentration variability over the Vietnamese coastal waters from the MERIS ocean color sensor (2002-2012). Remote Sens. Environ. 2017, 190, 217-232.

23. Gohin, F.; Druon, J.; Lampert, L. A five channel chlorophyll concentration algorithm applied to SeaWiFS data processed by SeaDAS in coastal waters. Int. J. Remote Sens. 2002, 23, 1639-1661.

24. Gurlin, D.; Gitelson, A.A.; Moses, W.J. Remote estimation of chl-a concentration in turbid productive waters-Return to a simple two-band NIR-red model? Remote Sens. Environ. 2011, 115, 3479-3490.

25. Mueller, J. Ocean color spectra measured off the Oregon coast: Characteristic vectors. Appl. Opt. 1976, 15, 394-402.

26. Qi, L.; Hu, C.; Duan, H.; Barnes, B.B.; Ma, R. An EOF-based algorithm to estimate chlorophyll a concentrations in Taihu Lake from MODIS land-band measurements: Implications for near real-time applications and forecasting models. Remote Sens. 2014, 6, 10694-10715.

27. Barnes, B.B.; Hu, C.; Cannizzaro, J.P.; Craig, S.E.; Hallock, P.; Jones, D.L.; Lehrter, J.C.; Melo, N.; Schaeffer, B.A.; Zepp, R. Estimation of diffuse attenuation of ultraviolet light in optically shallow Florida Keys waters from MODIS measurements. Remote Sens. Environ. 2014, 140, 519-532.

28. Fichot, C.G.; Sathyendranath, S.; Miller, W.L. SeaUV and SeaUV C: Algorithms for the retrieval of UV/Visible diffuse attenuation coefficients from ocean color. Remote Sens. Environ. 2008, 112, 1584-1602.

29. Craig, S.; Jones, C.; Li, W.; Lazin, G.; Horne, E.; Caverhill, C.; Cullen, J. Deriving optical metrics of coastal phytoplankton biomass from ocean colour. Remote Sens. Environ. 2012, 119, 72-83.

30. Fisheries and Oceans Canada. Database of the Environmental Data Management System (EDMS) from Maurice Lamontagne Institute (MLI); St. Lawrence Global Observatory's SLGO porta. Available online: http:/ / ogsl.ca (accessed on 12 November 2015).

31. Holm-Hansen, O.; Lorenzen, C.J.; Holmes, R.W.; Strickland, J.D.H. Fluorometric Determination of Chlorophyll. Journal Conseil International pour l'Exploration de la Mer 1965, 30, 3-15.

32. Welschmeyer, N.A. Fluorometric analysis of chlorophyll a in the presence of chlorophyll $\mathrm{b}$ and pheopigments. Limnol. Oceanogr. 1994, 39, 1985-1992.

33. NASA Goddard Space Flight Center, Ocean Ecology Laboratory, Ocean Biology Processing Group; Sea-viewing Wide Field-of-view Sensor (SeaWiFS) Ocean Colour Data. NASA OB.DAAC, Greenbelt, MD, USA. Available online: https:/ / oceandata.sci.gsfc.nasa.gov/SeaWiFS/L1 (accessed on 12 November 2015)

34. Bailey, S.; Werdell, P. A multi-sensor approach for the on-orbit validation of ocean color satellite data products. Remote Sens. Environ. 2006, 102, 12-23. 
35. Pahlevan, N.; Sarkar, S.; Franz, B.A. Uncertainties in coastal ocean color products: Impacts of spatial sampling. Remote Sens. Environ. 2016, 181, 14-26.

36. Devine, L.; Plourde, S.; Starr, M.; St-Pierre, J.F.; St-Amand, L.; Joly, P.; Galbraith, P.S. Chemical and Biological Oceanographic Conditions in the Estuary and Gulf of St. Lawrence during 2014; Technical report; Canadian Science Advisory Secretariat: Ottawa, ON, Canada, 2015.

37. Lee, Z.; Hu, C. Global distribution of Case-1 waters: An analysis from SeaWiFS measurements. Remote Sens. Environ. 2006, 101, 270-276.

38. NASA Goddard Space Flight Center, Ocean Ecology Laboratory, Ocean Biology Processing Group; year=2014 Sea-viewing Wide Field-of-view Sensor (SeaWiFS) Ocean Colour Data, NASA OB.DAAC, Greenbelt, MD, USA. Available online: https://oceandata.sci.gsfc.nasa.gov/SeaWiFS/Binned/Cumulative/RRS (accessed on 12 November 2015)

39. Goyens, C.; Jamet, C.; Schroeder, T. Evaluation of four atmospheric correction algorithms for MODIS-Aqua images over contrasted coastal waters. Remote Sens. Environ. 2013, 131, 63-75.

40. Stumpf, R.P.; Arnone, R.A.; Gould, R.W.; Ransibrahmanakul, V. A Partly Coupled Ocean-Atmosphere Model for Retrieval of Water-Leaving Radiance from SeaWiFS in Coastal Waters; Technical Report 22, NASA technical memorandum; NASA Goddard Space Flight Center: Greenbelt, MD, USA, 2003.

41. Bailey, S.W.; Franz, B.; Werdell, P.J. Estimation of near-infrared water-leaving reflectance for satellite ocean color data processing. Opt. Express 2010, 18, 7521-7527.

42. Ahmad, Z.; Franz, B.; McClain, C.R.; Kwiatkowska, E.J.; Werdell, J.; Shettle, E.P.; Holben, B.N. New aerosol models for the retrieval of aerosol optical thickness and normalized water-leaving radiances from the SeaWiFS and MODIS sensors over coastal regions and open oceans. Appl. Opt. 2010, 49, 5545-5560.

43. Ruddick, K.G.; De Cauwer, V.; Park, Y.J.; Moore, G. Seaborne measurements of near infrared water-leaving reflectance: The similarity spectrum for turbid waters. Limnol. Oceanogr. 2006, 51, 1167-1179.

44. Larouche, P.; Boyer-Villemaire, U. Suspended particulate matter in the St. Lawrence estuary and Gulf surface layer and development of a remote sensing algorithm. Estuar. Coast. Shelf Sci. 2010, 90, 241-249.

45. Legendre, P. lmodel2: Model II Regression. R package version 1.7-2. 2014. Available online: https:/ / cran.rproject.org/web/packages/lmodel2/lmodel2.pdf (accessed on 12 November 2015).

46. Szeto, M.; Werdell, P.J.; Moore, T.S.; Campbell, J.W. Are the world's oceans optically different? J. Geophys. Res. 2011, 116, doi:10.1029/2011JC007230.

47. Siegel, D.; Behrenfeld, M.; Maritorena, S.; McClain, C.; Antoine, D.; Bailey, S.; Bontempi, P.; Boss, E.; Dierssen, H.; Doney, S.; et al. Regional to global assessments of phytoplankton dynamics from the SeaWiFS mission. Remote Sens. Environ. 2013, 135, 77-91.

48. Darecki, M.; Kaczmarek, S.; Olszewski, J. SeaWiFS ocean colour chlorophyll algorithms for the southern Baltic Sea. Int. J. Remote Sens. 2005, 26, 247-260.

49. Mustapha, S.B.; Bélanger, S.; Larouche, P. Evaluation of ocean color algorithms in the southeastern Beaufort Sea, Canadian Arctic: New parameterization using SeaWiFS, MODIS, and MERIS spectral bands. Can. J. Remote Sens. 2012, 38, 535-556.

50. Garcia, V.M.T.; Signorini, S.; Garcia, C.A.E.; McClain, C.R. Empirical and semi-analytical chlorophyll algorithms in the south-western Atlantic coastal region (25-40 S and 60-45 W). Int. J. Remote Sens. 2006, 27, 1539-1562.

51. Oguz, T.; Ediger, D. Comparision of in situ and satellite-derived chlorophyll pigment concentrations, and impact of phytoplankton bloom on the suboxic layer structure in the western Black Sea during May-June 2001. Deep Sea Res. Part II Top. Stud. Oceanogr. 2006, 53, 1923-1933.

52. Werdell, P.J.; Bailey, S.W.; Franz, B.A.; Harding, L.W.; Feldman, G.C.; McClain, C.R. Regional and seasonal variability of chlorophyll-a in Chesapeake Bay as observed by SeaWiFS and MODIS-Aqua. Remote Sens. Environ. 2009, 113, 1319-1330.

53. Tang, S.; Chen, C.; Zhan, H.; Zhang, J.; Yang, J. An appraisal of surface chlorophyll estimation by satellite remote sensing in the South China Sea. Int. J. Remote Sens. 2008, 29, 6217-6226.

54. Wang, J.; Cota, G.F. Remote-sensing reflectance in the Beaufort and Chukchi seas: Observations and models. Appl. Opt. 2003, 42, 2754-2765.

55. Werdell, P.J.; Fargion, G.S.; McClain, C.R.; Bailey, S.W. The SeaWiFS Bio-Optical Archive and Storage System (SeaBASS): Current Architecture and Implementation. 2002. Available online: https://ntrs.nasa.gov/ archive/nasa/casi.ntrs.nasa.gov/20020091607.pdf (accessed on 23 April 2016). 
56. Maritorena, S.; Siegel, D.A.; Peterson, A.R. Optimization of a semianalytical ocean color model for global-scale applications. Appl. Opt. 2002, 41, 2705-2714.

57. Werdell, P.J.; Franz, B.A.; Bailey, S.W.; Feldman, G.C.; Boss, E.; Brando, V.E.; Dowell, M.; Hirata, T.; Lavender, S.J.; Lee, Z.; et al. Generalized ocean color inversion model for retrieving marine inherent optical properties. Appl. Opt. 2013, 52, 2019-2037.

58. Shang, S.; Dong, Q.; Hu, C.M.; Lin, G.; Li, Y.; Shang, S. On the consistency of MODIS chlorophyll a products in the northern South China Sea. Biogeosciences 2014, 11, 269.

59. Revelle, W. Psych: Procedures for Psychological, Psychometric, and Personality Research; R package version 1.7.8; Northwestern University: Evanston, IL, USA, 2017.

60. Venables, W.N.; Ripley, B.D. Modern Applied Statistics with S, 4th ed.; Springer: New York, NY, USA, 2002; ISBN 0-387-95457-0.

61. Akaike, H. Information theory and an extension of the maximum likelihood pri nciple. In Proceedings of the 2nd International Symposium on Information Theory, Budapest, Hungary, 2-8 September 1973; pp. 267-281.

62. Anderson, D.R.; Burnham, K.P. Avoiding pitfalls when using information-theoretic methods. J. Wildl. Manag. 2002, 66, 912-918.

63. Morel, A. In-water and remote measurement of ocean color. Bound.-Layer Meteorol. 1980, 18, $177-201$.

64. Mao, Z.; Stuart, V.; Pan, D.; Chen, J.; Gong, F.; Huang, H.; Zhu, Q. Effects of phytoplankton species composition on absorption spectra and modelled hyperspectral reflectance. Ecol. Inform. 2010, 5, 359-366.

65. Isada, T.; Hirawake, T.; Kobayashi, T.; Nosaka, Y.; Natsuike, M.; Imai, I.; Suzuki, K.; Saitoh, S.I. Hyperspectral optical discrimination of phytoplankton community structure in Funka Bay and its implications for ocean color remote sensing of diatoms. Remote Sens. Environ. 2015, 159, 134-151.

66. D'Alimonte, D.; Zibordi, G.; Berthon, J.F.; Canuti, E.; Kajiyama, T. Performance and applicability of bio-optical algorithms in different European seas. Remote Sens. Environ. 2012, 124, 402-412.

67. Kajiyama, T.; D'Alimonte, D.; Zibordi, G. Regional algorithms for European seas: A case study based on MERIS data. IEEE Geosci. Remote Sens. Lett. 2013, 10, 283-287.

68. Le, C.; Hu, C.; Cannizzaro, J.; English, D.; Muller-Karger, F.; Lee, Z. Evaluation of chlorophyll-a remote sensing algorithms for an optically complex estuary. Remote Sens. Environ. 2013, 129, 75-89.

69. Chang, C.H. Development of ocean color algorithms for estimating chlorophyll-a concentrations and inherent optical properties using gene expression programming (GEP). Opt. Express 2015, 23, 5417-5437.

70. Spyrakos, E.; Vilas, L.G.; Palenzuela, J.M.T.; Barton, E.D. Remote sensing chlorophyll a of optically complex waters (rias Baixas, NW Spain): Application of a regionally specific chlorophyll a algorithm for MERIS full resolution data during an upwelling cycle. Remote Sens. Environ. 2011, 115, 2471-2485.

71. Bélanger, S.; Carrascal-Leal, C.; Jaegler, T.; Larouche, P.; Galbraith, P. Assessment of Radiometric Data from a Buoy in the St. Lawrence Estuary. J. Atmos. Ocean. Technol. 2017, 34, 877-896.

72. IOCCG. Remote Sensing of Ocean Colour in Coastal, and Other Optically Complex, Waters In Reports of the International Ocean Colour Coordinating Group; IOCCG: Dartmouth, NS, Canada, 2000; Volume 3.

(C) 2018 by the authors. Licensee MDPI, Basel, Switzerland. This article is an open access article distributed under the terms and conditions of the Creative Commons Attribution (CC BY) license (http://creativecommons.org/licenses/by/4.0/). 